\title{
Analysis of Pharyngeal Airway Using Lateral Cephalogram vs CBCT Images: A Cross-sectional Retrospective Study
}

\author{
Pegah Bronoosh and Leila Khojastepour*
}

Department of Oral and Maxillofacial Radiology, Dental School, Shiraz University of Medical Science, Shiraz, Iran

\begin{abstract}
Background: As the basic biological relationship of form and function, changes in the normal pattern of nasopharyngeal space can profoundly affect the development of the craniofacial growth. The lateral cephalogram, part of the patient's normal records for orthodontic treatment, may show some of these changes either at the initial examination or later during treatment. The validity of the information the lateral cephalogram may present, have been questioned previously. The aim of this study was to assess correlation between the area and the volume measurements of pharyngeal airway size in a lateral cephalogram and a 3-dimensional (3D) cone-beam computed tomography (CBCT) scan in adolescent subjects. Materials and Methods: CBCT scan and a lateral cephalogram of 35 subjects which were taken within 1 week were included in this study. Airway area of the region of interest from the lateral cephalogram and airway volume over the same of region of interest from the CBCT scan were assessed for all patients. The correlation between the area and the volume measurements were evaluated statistically by Pearson's correlation coefficient test. Mann Whitney U Test was used for comparing the area and the volume measurements in different sex. Results: Strong correlation was found between lateral cephalogram and CBCT measurements of pharyngeal airway. $(\mathrm{r}=0.831)$. Conclusion: Pharyngeal airway area on a lateral cephalogram is correlated strongly with volumetric data on CBCT images. Henceforth the use of CBCT images for volume measurements in orthodontic patients can aid in the better evaluation of airways and acted as a diagnostic instrument in this area.
\end{abstract}

Keywords: Cephalogram, cone-beam computed tomography, pharyngeal airway space, three dimensional measurement.

\section{INTRODUCTION}

The relationship between respiratory pattern disorders and changes in craniofacial growth has been extensively debated in the literature [1, 2]. Neuromuscular adaptations, nasopharyngeal obstruction, growth, breathing, and speech are affected seriously by airway function $[1,3]$. Also, Upper airway dimensions have been considered contributing factors to obstructive sleep apnea [4]. This factor is very important especially in growing patients with skeletal discrepancies and clinical signs of adenoid faces. Some studies described that airway disorder is a common cause of malocclusion and leads to the classic appearance of adenoid face [5]. Other studies have evaluated the upper airway in patients with different skeletal patterns [6-10].

Although airway restrictions can clear spontaneously over time, their effects during periods of facial growth can have serious and long-lasting influence on dentition, speech, and craniofacial development which is best evaluated by experimental studies. So, orthodontists need credible diagnostic tools that provide precise information to both themselves and the medical specialists involved [11]. Only limited and subjective evaluations of possible airway problems are completed by the orthodontist, usually from a lateral cephalogram [9, 12-14].

*Address correspondence to this author at the Department of Oral and Maxillofacial Radiology, Dental School, Qasrodasht Street, Shiraz, Iran; Tel: +98-711-6270325; E-mail: khojastepour_1@yahoo.com
However, this diagnostic tool to examine the anatomical features of airway is inadequate [11]. A 2D representation of a 3-dimensional (3D) structure causes severe limitations as distortion, differences in magnifications, superimposition of the bilateral craniofacial structures [15-17]. Another limitation of this radiograph is the lack of information about crosssectional area and volume.

Recently, CBCT technology aided in the evaluation of airways and acted as a diagnostic instrument in this area. 3D object is reconstructed from raw data, so magnification is not an issue. The generated image by CBCT is isotropic and linear and angular measurements are reliable and anatomically accurate [18]. However this technology is not as available as conventional radiographs, besides, orthodontic patients are not routinely referred for CBCT examination according to guidelines [19].

Henceforth, it was decided to assess the correlation between the area and the volume measurements of pharyngeal airway in a lateral cephalogram and a 3D CBCT scan in adolescent subjects.

\section{METHODS AND MATERIALS}

In this retrospective, cross-sectional study, all consecutive adolescents referred to a private imaging center for CBCT image were included over 8 months. The project was approved by the Committee on Research at Shiraz University of medical science, International branch (approval no\# 8691036). 
All subjects with a CBCT scan and a lateral cephalogram taken within 1 week were included in the study. CBCT scans in the present study were taken in upright position to avoid the airway space modification between radiographs taken in supine and upright positions. The most common reason for CBCT referral was temporomandibular joint evaluation and impacted tooth. Subjects were excluded if they wore a bite splint, or had a documented craniofacial anomaly or previous orthognathic surgery or were less than 20 years old. The convenience sample size was used in this study and post analysis power will be assessed based on correlation coefficient value at significant level $\alpha=0.05$.

98 possible subjects were examined, and 35 met the inclusion criteria. The most common reason for exclusion of a subject was that the 2 sets of images were not taken within 1 week of each other.

Lateral 2D cephalograms were taken by Cranex D (Soredex, Finland) under standardized conditions $(\mathrm{KVP}=70$ \& $\mathrm{mA}=10$ ) with a magnification of $9.8 \%$. The cephalograms were then scanned at 150 to $300 \mathrm{dpi}$ for analysis.

Three-dimensional CBCT volume scans were obtained by using the same NewTom VGi computed tomography machine (Quantitative Radiology, Verona, Italy) in maximum field of view $(\mathrm{FOV}=15 \times 15)$

Lateral cephalogram studies of the airway have included both linear and area measurements based on specific cephalometric landmarks.

The following anatomic structures as seen on the lateral cephalogram were used as boundaries of the pharyngeal airway for all subjects: (1) The superior border was defined by the edge of the hard palate to the posterior of the pharynx (extension of ANS to PNS); (2) The inferior border the tip of the epiglottis on a plane parallel to line 1. (3) The plane perpendicular to the line $1 / 2$ from PNS extending to the inferior border. These same planes were transferred into the 3D scan to measure airway volume over the same anatomic boundaries (Fig. 1).

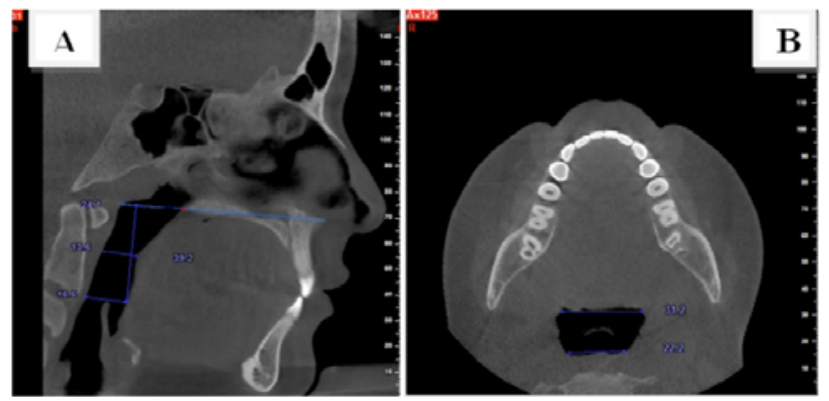

Fig. (1). (A) Sagittal cross section through mid sagittal plane shows the superior \& inferior border of region of interest. (B) Axial cross section through epiglottis show area of region of interest at the level of epiglottis.

The CBCT axial reconstruction plane was re-oriented for each patient based on three reference planes: axial plane, coronal plane, sagittal plane. Airway volumes were determined from the summation of the airway area by using 0.8 to $1 \mathrm{~mm}$ axial CBCT slices over the vertical height of the pharyngeal airway determined from the lateral cephalogram.
The following measurements of the pharyngeal airway space were made for each case: (a) 2D measurements; airway area of the region of interest from the lateral cephalogram; (b) 3D measurements; airway volume over the same of region of interest from the CBCT scan, with all segmented $3 \mathrm{D}$ volumes in this study at the same scale and magnification for comparison.

\section{Statistical Analysis}

Bivariate correlation coefficient (r) was determined by Pearson correlation coefficient test to assess correlation between the area and the volume measurements. Mann Whitney $U$ test was used for assessing the sex differences in $2 D$ and 3D measurements. All statistical analyses were performed using SPSS software 18 (Chicago, USA).

\section{RESULTS}

The airway area and volume were measured for all subjects who met the inclusion criteria. The sample consisted of 23 female and 12 male with mean age of $21.74 \pm 2.63$ years old. Post analysis power based on correlation coefficient value $r=0.831$ at significant level $\alpha=0.05$ was $99 \%$.

There was more variability in volume than in area as a percentage of the means. There was also a much wider range in the volume determined as a percentage of the means. (Table 1) Correlation coefficient $r=0.831$ suggest a positive association between two methods of measurements (Table $\mathbf{1}$ ).

The Comparison of pharyngeal air way 3D and 2D measurements between different sexes were summarized in Table $\mathbf{2}$. Based on available data both area and volume of pharyngeal airway were significantly greater in male patients.

\section{DISCUSSION}

Previous studies on airway, attempted to quantify airway restriction and function by morphologic or functional measurements [13, 20-23]. Lateral Cephalograms have been mostly used for the upper airway evaluation in orthodontics, with specific landmarks to characterize the airway [23].

This study was primarily designed to evaluate the clinical value of cephalograms as a tool for pharyngeal airway assessment, compared with quantification of the 3D morphology of the pharyngeal airway with CBCT scans.

The airway in adolescents' changes rapidly; therefore, the CBCT scan and the lateral cephalogram needed to be taken at the same time for accurate comparison. Even though the cutoff point for the images was 1 week, most subjects had images taken at the same time.

The overall patency of pharyngeal airway can be evaluated through cephalogram. However, there is a tendency to believe that $2 \mathrm{D}$ view of the airway space does not give an accurate indication of the complexity of this structure or its true size $[11,16,17]$. Our results indicate that, the lateral cephalogram can provide valuable information about severe restrictions and morphology of airway space. Aboudara et al. also found a moderately high $(\mathrm{r}=0.75)$ correlation between airway area and volume in lateral cephalograms and CBCT; the larger the area, the larger the volume [13]. The study conducted by Lenza et al. also presented a good correlation 
Table 1. Descriptive statistics of airway area and volume.

\begin{tabular}{|c|c|c|c|c|c|c|}
\hline Measurements & $\mathbf{n}$ & Mean \pm SD & Max & Min & P value \\
\hline \hline Area $\mathrm{mm}^{2}$ & 35 & $325.24 \pm 85.38$ & 540.13 & 205.2100 & 0.831 & 0.000 \\
\hline Volume $\mathrm{mm}^{3}$ & 35 & $3398.11 \pm 1226.85$ & 5876.12 & 1835.23 & \\
\hline
\end{tabular}

Table 2. Comparison of pharyngeal air way 3D and 2D measurements, between different sexes.

\begin{tabular}{|c|c|c|c|}
\hline Sex & Volume in CBCT 3D & $\mathbf{P}^{*}$ & Area in Cephalogram 2D \\
\hline \hline Male & $4429.8(4198 \pm 1008)$ & \multirow{2}{*}{0.007} & $380.8(370.1 \pm 60.9)$ \\
\cline { 1 - 2 } Female & $2565.2(2980 \pm 1134.5)$ & & $282.4(301.9 \pm 88)$ \\
\hline
\end{tabular}

"Mann Whitney Test

$(0.8<\mathrm{r}<0.9)$ between area and volume in the upper part of the velopharynx [15].

Airway function can affect on facial morphology over a long time. Although there is still some controversy about airway function and its effect on facial morphology, nasopharyngeal impairment was found in most of patients with increased anterior face height. This can have adverse consequences on dental function and esthetics [3, 21-25].

This is a starting point for the ability of anesthesiologists to manage the airway in patients known or suspected to be difficult for intubation. In these cases a lateral head film may be of more value than clinical tools such as history and examination.

Although present study showed strong correlation between lateral cephalogram and CBCT images, CBCT technology gives a new insight into the anatomical landmarks not visible on 2D cephalograms and allows to measure real distances and angles that helps to correctly evaluate growth and development of the craniofacial complex [26]. For instance, clinical malocclusion is a 3D manifestation; however, a clinician usually focuses on anteroposterior correction instead of evaluating vertical and transverse dimensions as well. So, besides airway assessment in $3 \mathrm{D}$ aspect, CBCT images have the potential of a 3D malocclusion description.

Functional tests did not performed in this study, so introducing a threshold to show to what extent airway volume can affect the function is not possible. Further studies are needed to address this question.

Some studies admit that resistance to airflow is related to both size and shape of airway passageway [14, 27]. 3D evaluation of airway may also better discriminate the pharyngeal airway shape and help to diagnose the airway problems more effectively.

\section{CONCLUSION}

Based on the limited sample used in the present study, the results suggest that the pharyngeal airway area on a lateral cephalogram and its true volumetric size from a CBCT scan are strongly correlated. Further studies including functional tests should be conducted to understand the extent to which airway volume may affect function.

\section{CONFLICT OF INTEREST}

The authors confirm that this article content has no conflict of interest.

\section{ACKNOWLEDGEMENTS}

We would like to thank the vice-chanceller of Shiraz University of Medical Sciences, International Branch, for supporting this research. This paper has been extracted from the Ph.D. thesis of SH.CH. on research conducted under supervision by P.B. and advisory of L.KH. We also thank Dr. M. Vossoughi from the Dental Research Development Center for the statistical analysis.

\section{REFERENCES}

[1] McNamara JA. Influence of respiratory pattern on craniofacial growth. Angle Orthod 1981; 51(4): 269-300.

[2] Vig KW. Nasal obstruction and facial growth: the strength of evidence for clinical assumptions. Am J Orthod Dentofac Orthop 1998; 113(6): 603-11.

[3] Osorio F, Perilla M, Doyle DJ, Palomo JM. Cone beam computed tomography: an innovative tool for airway assessment. Anesth Analg 2008; 106: 1803-7.

[4] Haskell JA, McCrillis J, Haskell BS, Scheetz JP, Scarfe WC, Farman AG. Effects of mandibular advancement device (MAD) on airway dimensions assessed with cone-beam computed tomography. Semin Orthod 2009; 15: 132-58.

[5] Alves M Jr, Franzotti ES, Baratieri C, Nunes LK, Nojima LI, Ruellas AC. Evaluation of pharyngeal airway space amongst different skeletal patterns. Int J Oral Maxillofac Surg 2012; 41(7): 814-9.

[6] Grauer D, Cevidanes LSH, Styner MA, Ackerman JL, Proffit WR. Pharyngeal airway volume and shape from cone-beam computed tomography: Relationship to facial morphology. Am J Orthod Dentofac Orthop 2009; 136: 805-14.

[7] Iwasaki T, Saitoh I, Takemoto Y, et al. Evaluation of upper airway obstruction in Class II children with fluid-mechanical simulation. Am J Orthod Dentofac Orthop 2011; 139: e135-45.

[8] Kim YJ, Hong JS, Hwang YI, Park YH. Three-dimensional analysis of pharyngeal airway in preadolescent children with different anteroposterior skeletal patterns. Am J Orthod Dentofac Orthop 2010; 137: 306.e1-11.

[9] Muto T, Yamazaki A, Takeda S. A cephalometric evaluation of the pharyngeal airway space in patients with mandibular retrognathia and prognathia, and normal subjects. Int J Oral Maxillofac Surg 2008; 37: 228-31.

[10] Zhong Z, Tang Z, Gao X, Zeng XL. A comparison study of upper among different skeletal craniofacial patterns in nonsnoring Chinese children. Angle Orthod 2010; 80: 267-74. 
[11] Vig PS, Hall DJ. The inadequacy of cephalometric radiographs for airway assessment. Am J Orthod 1980; 77: 230-3.

[12] Farid MM, Metwalli N. Computed tomographic evaluation of mouth breathers among paediatric patients. Dentomaxillofac Radiol 2010; 39: 1-10.

[13] Aboudara C, Nielsen I, Huang JC, Maki K, Miller AJ, Hatcher D. Comparison of airway space with conventional lateral head films and 3-dimensional reconstruction from cone-beam computed tomography. Am J Orthod Dentofac Orthop 2009; 135(4): 468-79.

[14] Sorensen H, Solow B, Greve E. Assessment of the nasopharyngeal airway. A rhinomanometric and radiographic study in children with adenoids. Acta Otolaryngol 1980; 89: 227-32.

[15] Lenza MG, Lenza MM, Dalstra M, Melsen B, Cattaneo PM. An analysis of different approaches to the assessment of upper airway morphology: a CBCT study. Orthod Craniofac Res 2010; 13(2): 96-105.

[16] Baumrind S, Frantz RC. The reliability of head film measurements.2. Conventional angular and linear measures. Am J Orthod 1971; 60: 505-17.

[17] Ahlqvist J, Eliasson S, Welander U. The effect of projection errors on cephalometric length measurements. Eur J Orthod 1986; 8: 1418.

[18] Baumgaertel S, Palomo JM, Palomo L, Hans MG. Reliability and accuracy of cone-beam computed tomography dental measurements. Am J Orthod Dentofac Orthop 2009; 136(1): 19-25.

[19] Brown J, Jacobs R, Levring JE, et al. Basic training requirements for the use of dental CBCT by dentists: a position paper prepared by the European Academy of Dento MaxilloFacial Radiology. Dentomaxillofac Radiol 2014; 43(1): 20130291.

[20] Schwab RJ, Goldberg AN. Upper airway assessment: radiographic and other imaging techniques. Otolaryngol Clin North Am 1998; 31: 931-68.

[21] Linder-Aronson S. Adenoids: Their effect on mode of breathing and nasal airflow, and their relationship to characteristics of the facial skeleton and the dentition. A biometric, rhinomanometric, and cephalometro-radiographic study on children with and without adenoids. Acta Otolaryngol Suppl 1970; 265: 1-132.

[22] Linder-Aronson S, Henrikson C. Radiocephalometric analysis of anteroposterior nasopharyngeal dimensions in 6 to 12-year-old mouth breathers compared with nose breathers. ORL J Otorhinolaryngol Relat Sec 1973; 35: 19-29.

[23] Schwab R. Upper airway imaging. Clin Chest Med 1998; 19: 3354.

[24] Nielsen I. Vertical malocclusions: etiology, development, diagnosis, and some aspects of treatment. Angle Orthod 1991; 61: 247-60.

[25] Solow B, Siersback-Nielsen S, Greve E. Airway adequacy, head posture, and craniofacial morphology. Am J Orthod 1984; 86: 21423.

[26] Mah JK, Huang JC, Choo H. Practical applications of cone-beam computed tomography in orthodontics. J Am Dent Assoc 2010; 141 (Suppl 3): 7S-13S.

[27] MontgomeryW, Vig P, Staab E, Matteson S. Computed tomography: a three-dimensional study of the nasal airway. Am J Orthod 1979; 76: 363-75.

(C) Bronoosh and Khojastepour; Licensee Bentham Open.

This is an open access article licensed under the terms of the Creative Commons Attribution Non-Commercial License (http://creativecommons.org/licenses/by-nc/3.0/) which permits unrestricted, non-commercial use, distribution and reproduction in any medium, provided the work is properly cited. 